\title{
Cinema-going at the Antwerp Zoo (1915-1936): A Cinema-concert Program Database
}

\section{Arts and Media}

\author{
Leen Engelen \\ LUCA School of Arts / KU Leuven, Genk, Belgium \\ leen.engelen@luca-arts.be \\ Thomas Crombez \\ Royal Academy of Fine Arts, Antwerp, Belgium \\ thomas.crombez@ap.be \\ Roel Vande Winkel \\ KU Leuven / LUCA School of Arts, Louvain, Belgium \\ roel.vandewinkel@kuleuven.be
}

\begin{abstract}
This paper outlines the genesis of the cinema-concert program database of the Belgian movie theatre Cinema Zoologie $\left(1915^{-1936)}\right.$ deposited in the DANS repository. First, it provides a detailed account of the historical sources and the data collection process. Second, it explains the structure of the database and the coding that was used to enter the data. Finally, the strengths and weaknesses of the database are discussed and its potential for future research is highlighted.
\end{abstract}

\section{Keywords}

cinema-going - cinema culture - film - concert - Belgium - First World War - film programs - classical music 
- Related data set "Cinema Zoologie 1915-1936: A film programming database" with DOI https://www.doi.org/10.17026/dans-x4q-jvgz in repository "DANs"

- See the showcase of the data in the Exhibit of Datasets: https://www.dans datajournal.nl/rdp/exhibit.html? showcase=engelen2020

\section{Introduction}

This paper outlines the genesis, data and structure of a cinema-concert program database of the Belgian movie theatre Cinema Zoologie (1915-1936) deposited in the DANS repository. Cinema Zoologie opened in October 1915, in then German-occupied Antwerp and remained open continuously until May 1936. It was owned and operated by the Royal Zoological Society of Antwerp and located at the premises of the Antwerp Zoological Garden (Statieplein 1, Antwerp). The venue was built as a concert hall in 1897 and was home to the Symphonic Orchestra of the Zoological Society. In 1915 it was transformed into a movie theatre: the podium was altered, a screen was installed in front of the large organ, and a projection booth was built on the rear balcony (Engelen \& Vande Winkel, 2016). The venue seated 2100 to 2400 people. The mixed program consisted of films and classical music pieces. The latter were initially performed by a small orchestra of 8 musicians. After the introduction of mechanical sound in the late 1920s, the music program diminished and was finally abolished. As of 1916, a weekly program booklet was printed and sold to the audience. This publication continued to exist until the closing of the theatre in 1936 .

It must be mentioned that it is rare for such a large collection of film programs to survive. Among other things, this is certainly due to the unusually high quality of this particular publication (e.g. the artistic cover design, highquality contents such as multiple page summaries for the main films,...). The quality was in tune with the overall public communication of the Zoological Society, which targeted a predominantly bourgeois audience. Nevertheless, it is still an ephemeral publication, and therefore the preservation of a near to complete collection is all the more exceptional. All of this explains why the collection of weekly programs of Cine Zoologie and the database built on it, is, by international standards, a unique resource about film programming in the heydays of silent cinema and the early years of sound film.

\section{Sources}

This collection of weekly programs forms the archival backbone of the database. They are part of the company archive of the Royal Zoological Society 
of Antwerp now held by the Antwerp City Archive (FelixArchief, numbers 1968\#1 to 1968\#1007). The first issue was published in the first week of February 1916, some three and a half months after the opening of the theatre. The last program was published in May 1936. For the first three and a half months, the program data in the dataset are based on two hand-written registers

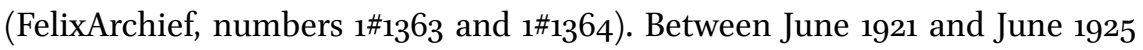
(not coincidentally a period of financial hardship for Cinema Zoologie), the program was no longer published as a separate publication, but as a doublepage insert in the Belgian French-language movie magazine Ciné-Revue, in its Dutch-language sister magazine De Cinema (later published under the title Film-Revue) and/or in the Dutch language movie magazine Cinemawereld. Between July 1925 and June 1930, the weekly programs were no longer published separately, but were only listed in the film section of the local newspaper Het Handelsblad van Antwerpen and/or the film magazine Weekblad Cinema. As of September 1930, the program was again published as a separate publication. For the 1930s sporadic gaps in the collection are filled with data published in Het Handelsblad or Weekblad Cinema. While all other sources list all the films and musical pieces, the latter only advertised the main film.

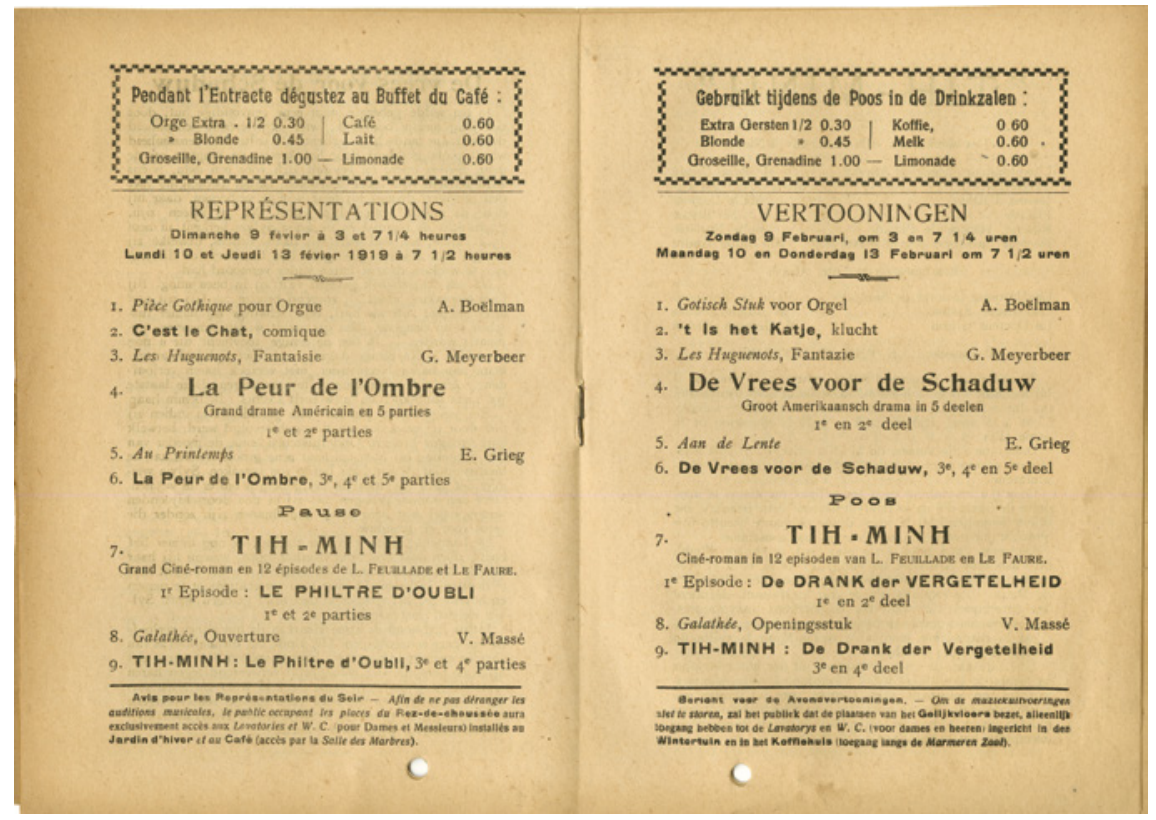

FIGURE 1 EXample of the original archival source material on which the database is based FELIXARCHIEF, 1966\#144. PROGRAM CINEMA ZOOLOGIE, 9 FEBRUARY 1919 
Cinema Zoologie was open 3 to 5 days each week (the number varying over the years). On the other days, the venue was used for different types of events, such as symphonic concerts and recitals, lectures, exhibitions or sports games (e.g. during the 1920 Olympic Games). These events are excluded from the database.

The data were entered manually into the database, a process involving several researchers: next to the project's supervisors Leen Engelen and Roel Van de Winkel, two students from the Catholic University of Leuven participated in the data collection (Cosemans and Engelen, 2015; Rombauts and Engelen, 2015). Combining the sources listed above enabled us to compile a nearcomplete database of the program of Cinema Zoologie, from 1915 to 1936.

Once the database of the film and music programs was complete, additional data were entered. The film titles were listed in French and/or Dutch in the published programs of Cinema Zoologie. The Belgian distributor usually chose those French/Dutch titles and they sometimes differed substantially from the (English, French, German, Danish, ...) original title. Printed summaries and details about the director and the cast allowed us to identify a substantial amount of the films. This time-consuming identification process was done manually with the help of specialized online databases such as imdb.com or cinemacon text.nl, dfi.dk for Danish films, filmportal.de and earlycinema.dch.phil-fak.unikoeln.de for German films, www.sfi.se/en-GB/Swedish-film-database for Swedish films and bnf.fr, filmographie.fondation-jeromeseydoux-pathe.com and cineressources.net for French films. We have only identified films if we had an exact title match or at least two clues (for instance a translated title and the name of a lead actor or a summary of the plot). Sometimes we retrieved these clues from additional sources such as newspapers or film magazines advertising the same title with additional information. Online archives such as belgica press.be or delpher.nl were very useful. For each identified film, the original title, the name of the director(s), the year in which the film had its international premiere, the country of origin and the production company or companies were entered in the database. For the films available on imdb.com, we included a link to the film's record on IMDb in the database. For the music pieces (already advertised in their original language) no additional information was added.

We used an additional field ('description') in the database to add all other information mentioned in the programs that was of value for the researchers: e.g., information about how certain films were advertised, about the composers of the music, special soloists, or upcoming programs. We copied this information verbatim from the historical sources. 


\section{The Dataset}

- Cinema Zoologie 1915-1936 deposited at DANS - Dor:https://www.doi .org/10.17026/dans-X4q-jvgz

- Temporal coverage: $1915^{-1936}$

The dataset consists of 5469 individual records (films, music pieces and occasional theatre performances), forming 898 cinema-concert programs. Each record (= each line) in the dataset corresponds to one program element from a Cinema Zoologie program. This can be a film showing, a musical performance, or a theatrical number. The type of event is indicated in the 'type' field. Some of the dataset's fields are specific to film showings (e.g. 'director'); hence they are left empty in the case of musical or theatrical performances.

Each record has the following fields: 'number', 'type', 'original title', 'Dutch title, 'French title', 'IMDb identifier', 'director', 'year', 'country', 'producer, 'program identifier', 'start date', 'end date' and description. When a field is left empty, this means that it was not applicable (like 'director' in case of a musical number) or that the information was not available to the researchers due to a lack of information in the archival sources.

Number

Type

Original title

Dutch title

French title

IMDb identifier

Director

Year

Country
Fixed record number

The type of program element ( $\mathrm{F}$ for film, $\mathrm{M}$ for musical performance, $\mathrm{T}$ for theatrical performance)

The title of the film (or musical composition, or theatre show) in its original language

The Dutch title used for presenting the film in the Cinema Zoologie program

The French title used for presenting the film in the Cinema Zoologie program

The URL that identifies this particular film at the Internet Movie Database (IMDb)

The director(s) of the film. When more than one director was involved, the names are separated by semicolons (e.g. Max Obal; Rudolf Walther-Fein)

The year when the film was originally released (internationally, not just in Belgium)

The country (or countries) where the film was produced. In case of co-productions, multiple countries are separated by a slash (e.g. D / F for Germany / France). Belgium (B), Switzerland (CH), Denmark (DK), Spain(E), Italy (I), 
Morocco (MA), United States (USA), India (IND), Japan (J), The Netherlands (NL), Poland (PL), Russia (RUS), Sweden (S), South Africa (ZA), Great Britain (UK)

Producer The company or companies that produced the film

Program identifier The archival record number of the program booklet containing the information for this record

Start date

The date of the first screening (or performance), using the format dd-mm-yyyy

End date

Description

The date of the last screening (or performance), using the format dd-mm-yyyy

Additional information (in French or Dutch) about the film, given in the program booklet

The dataset is stored in the tab-separated values (TSv) format. A Tsv file encodes a number of records that may contain multiple fields. Each record is represented as a single line. Each field value is represented as text. Fields in a record are separated from each other by a tab character.

We chose TSV over more complicated database formats, such as a relational database, because of the small scale of the project and budgetary constraints. Furthermore, TSv files have the advantage of being stored as simple text files. Thus, the dataset is available for quick consultation without the need for specialized software. (TSV is a popular method of data interchange among databases and spreadsheets and word-processors. It is the lowest common denominator in many cases between two different applications.)

We also chose TSV as an alternative to the common comma-separated values (csv) format, which often causes difficulties because of the need to escape commas, which occur frequently in our dataset (e.g. in film titles).

The text encoding of the TSV file is Unicode (UTF-8), which was chosen because of its ubiquity and its ability to encode all of the relevant languages (including Dutch, French, English, German, Swedish, and Danish).

\section{Availability}

Part of the dataset is accessible on the trilingual website that makes available the digital archive of Cinema Zoologie: cinemazoologie.be. This site was commissioned by the Royal Zoological Society of Antwerp as part of the celebrations for their $175^{\text {th }}$ anniversary in 2018. The main goal of this website is to make available the digitized program booklets to the public. These are then connected to the corresponding elements in the database. This database is limited 
because it only comprises the data based on the program booklets (Engelen \& Vande Winkel, 2016); it excludes, e.g., the programs for $1925^{-1930}$, which are retrieved from newspapers instead of program booklets. The search possibilities for this reduced dataset are limited, and the dataset is not available for downloading through this site.

The complete database is now deposited at DANs: https://www.doi.org/ 10.17026/dans-X4q-jvgz.

\section{Strengths and Weaknesses of the Database}

The completeness and the level of detail of the database is, without doubt, a strong point. The database holds data on every program in Cinema Zoologie between 1915 and 1936. Thanks to this feature it provides insight, on a micro level, into many larger film historical phenomena, such as the rise of the feature film in the 1910s, the impact of the First World War on film programming and distribution, hierarchies of cultural tastes, or the gradual introduction of sound in the late 1920s. These major evolutions in film history have been described in film historical reference works, but have so far seldom been studied on the level of one specific theatre in a peripheral geographic area such as Flanders, Belgium. This database enables this type of research. The dataset has been used (in combination with other datasets and archival sources) to research (transnational) film distribution and lends itself to data aggregation (Engelen, 2016; Engelen \& Vande Winkel, 2018).

Despite its overall completeness, some data are missing. This makes it difficult to use the dataset as a source for statistical computations. Especially for the 1910s, the identification of the different short films on the program remains incomplete. As any historian of early cinema realizes, the number of lost films from this era is very high, further complicating identification (Cherchi Usai, 2019). Based on the French or Dutch titles listed in the printed programs (often ad hoc and very creative translations of the original titles), the original titles were manually researched with the help of a number of specialized online databases (cf. supra). When additional information was available from the programs (for instance mentions of actors, country of origin, production company, director or plot), this was used to substantiate identification. This information is then also copied verbatim in the 'description' field. Despite our efforts, for the 1910s a limited number of films remains unidentified. Starting in the late 1910 and, definitely, with the final breakthrough of the feature film in the early 1920s, this shortcoming is largely solved as most of the international feature films are easily identifiable through the Internet Movie Database. 
An additional potential weakness of the database is the screening dates (identified with a start date and an end date). Overall, the program of Cinema Zoologie changed every week. However, next to the weekly changing program for a paying audience, a special program for the members of the Zoological Society was organized once or twice a week (the frequency changing over the years) between 1915 and 1926 (when the special screenings for members stopped). Depending on the availability of the sources, these programs are added to the database. This explains that, for some years, the dataset holds data for more than one program per week. The program for members was usually a slightly shorter version of the regular program. Because of this variation in the member/non-member program (the programs being linked to different dates) and because Cinema Zoologie was only open on selected days each week, the dates in the database (start date and end date of the program) usually correspond to a period of fewer than 7 days, while they still refer to a weekly changing program. This feature brings to the foreground shorter periods with exceptional screening intensity, such as the Holy Week and Easter when longer feature films (multiple reel passion plays or bible films in the 1910s) were scheduled on additional days. While this adds to the granularity of the dataset, it may complicate analysis based on date or the number of screenings for each film. The latter is another weak point of the database: where the data on the exact number of weekly screenings for each program (taking into account the number of days and the number of screenings each day) were too incomplete and unreliable, these data were omitted from the final database.

Overall, we would advocate to combine a quantitative with a qualitative approach and use the dataset in combination with the archival sources made available on cinemazoologie.be.

So far, the database has only been used for research on film programming and distribution. While for over a decade, the programs were constructed following a cinema-concert formula, the database holds quite some information on the music program as well. Its potential for research on musical culture and taste, for example, is hitherto untapped.

\section{References}

Cherchi Usai, P. (2019). Silent cinema. A guide to study, research and curatorship (3rd ed.). London, etc.: Bloomsbury (BFI).

Cosemans, M., \& Engelen, L. (Supervisor) (2015). Cinema Zoologie. Historiek en programmering tijdens de overgangsperiode naar de geluidsfilm (thesis). Faculty of Social Sciences, Katholieke Universiteit Leuven, Leuven. 
Engelen, L. (2016). België verdeeld. Filmdistributie in bezet België(1914-1918). Tijdschrift voor Mediageschiedenis 19(1), 5-21. DoI: http://doi.org/10.18146/2213-7653.2016.246

Engelen, L., \& Vande Winkel, R. (2016). A captivated audience. Cinema-going at the zoological garden in occupied Antwerp, 1915-1918. First World War Studies 7(3), 243264. D OI: https://www.doi.org/10.1080/19475020.2017.1315315

Engelen, L., \& Vande Winkel, R. (2018). Het filmaanbod van Cine Zoologie (19301936): een casestudy naar filmverdeling en -programmatie in de jaren dertig. HistoriANT 6 - 2018. Jaarboek voor Antwerpse Geschiedenis, 83-103. Antwerpen: Gompel \& Svacina.

Rombauts, L., \& Engelen, L. (Supervisor). (2015). Cinema Zoologie. Historiek en programmering tijdens de Eerste Wereldoorlog (thesis). Faculty of Social Sciences, Katholieke Universiteit Leuven, Leuven. 